\title{
Effects of high-voltage electrostatic field on the freezing behavior and quality of pork tenderloin
}

Guoliang Jia ${ }^{\text {a,b }}$, Xiangli He ${ }^{\mathrm{a}}$, Satoru Nirasawa ${ }^{\mathrm{d}}$, Eizo Tatsumi ${ }^{\mathrm{d}}$, Hongjiang Liu ${ }^{\mathrm{c}}$, Haijie

$$
\mathrm{Liu}^{\mathrm{a}, \mathrm{b}, *}
$$

${ }^{\mathrm{a} C}$ College of Food Science and Nutritional Engineering, China Agricultural University, Beijing 100083, China

${ }^{\mathrm{b}}$ Beijing Advanced Innovation Center for Food Nutrition and Human Health, China Agricultural University, Beijing 100083, China

${ }^{\mathrm{c} C o l l e g e}$ of Science, China Agricultural University, No. 17 Qinghuadonglu, Haidian District, Beijing 100083, China

${ }^{\mathrm{d} J a p a n}$ International Research Center for Agricultural Sciences, Tsukuba 305-8686, Japan

*Corresponding author. Tel: +86-10-6273-7331; Fax: +86-10-6273-7331

E-mail: liuhaijie@cau.edu.cn

Running title: Maintaining the quality of frozen pork using HVEF 
Abstract: This study investigated the effects of a high-voltage electrostatic field (HVEF) on the freezing behavior and quality maintenance of pork tenderloin. Based on the freezing behavior of deionized water (DW) under both $\mathrm{AC}$ and $\mathrm{DC}$ conditions, the freezing of pork samples using DC treatment was examined. It was found that the freezing point $\left(T_{\mathrm{m}}\right)$ and phase-transition time (crystallization time, $t_{\mathrm{c}}$ ) of the meat varied with increasing voltage. The water-holding capacity of samples treated by 10 $\mathrm{kV}$ exceeded that of the control group, which was proven using low-field nuclear calorimetry (LF-NMR) and differential scanning calorimetry (DSC). The total area of ice crystal for the cross sections of pork tenderloin treated with $10 \mathrm{kV}$ HVEF was much smaller than that without HVEF. Microstructural observations indicated that freezing assisted by $10 \mathrm{kV}$ HVEF was superior to freezing without $\mathrm{HVEF}$ in maintaining the quality of frozen pork.

Keywords: high-voltage electrostatic field; pork tenderloin; freezing behavior; meat quality; ice crystal

Chemical compounds studied in this article:

Sodium iodoacetate (PubChem CID: 5239); potassium chloride (PubChem CID: 4873) 


\section{Introduction}

As one of the most efficient methods for food preservation, freezing plays a vital role in ensuring the safety of exported meat products, which are worth at least US\$13 billion globally (Leygonie et al., 2012). However, the ultrastructure of meat can be easily damaged by the formation of large ice crystals; these affect certain biochemical reactions as well as quality parameters, such as color and moisture content. Many large ice crystals form when a sample's temperature is maintained at the solid-liquid equilibrium ( $\left.T_{\mathrm{m}}\right)$ for an extended period; thus, the $T_{\mathrm{m}}$ and phase-transition time are factors that determine product quality in the frozen food industry. A large number of small ice crystals and a short phase-transition time for the food matrix in meat, vegetables, and fruit - as well as for pharmaceutical products, including drugs and vaccines - are necessary to satisfy quality demands. High-pressure freezing is used to reduce the formation of ice I and increase the formation of ice II-IX; at these stages, ice does not increase in volume, thereby reducing tissue damage (Li \& Sun, 2002). In high-pressure freezing experiments, the phase-transition time has been found to be shorter than at atmospheric pressure (Otero \& Sanz, 2006). However, high-pressure freezing is expensive. In addition, radiofrequency was exploited by Anese et al. (2012) to assist pork freezing. Fewer intercellular voids were found by using radiofrequency assisted cryogenic freezing than by cryogenic freezing. Xanthakis et al. (2014) found that microwave field assisted freezing of pork decreased the average ice crystal size by $62 \%$.

A high-voltage electrostatic field (HVEF) has been used to control ice formation 
when freezing foods (Orlowska et al., 2009; Wei et al., 2008; Xanthakis et al., 2013). The plate electrode has been designed to control water ice nucleation and reduce ice crystal size of pork by the Alain Le-Bail' team (Orlowska et al., 2009; Xanthakis et al., 2013). The nucleation and crystallization process occurs when the Gibbs free energy for a system is negative $(\Delta G<0)$. For a spherical crystallite with no applied electrostatic field, $\Delta G_{0}=\Delta G_{s}+\Delta G_{V}=4 \pi \mathrm{r}^{2} \gamma-\frac{4}{3} \pi \mathrm{r}^{3} \Delta G_{v}$; for a spherical crystallite in an electrostatic field, $\Delta G_{E}=4 \pi \mathrm{r}^{2} \gamma-\frac{4}{3} \pi \mathrm{r}^{3}\left(\Delta G_{v}+P E\right)$. This indicates that a system will freeze more easily with the application of an electric field (Orlowska et al., 2009). Further, Wei et al. (2008) determined that water molecules are induced to align in an electrostatic field; under that condition, the direction of water's permanent dipole moment is the same as $E$ (the angle between the permanent dipole moment and $E$ is 0 or $2 \pi)$. Shevkunov and Vegiri (2002) calculated that the water cluster converged into an almost aligned state at the electric field strength of $1.5 \times 10^{7} \mathrm{~V} / \mathrm{m}$.

For a considerable time, researchers have been investigating HVEF technology as one of the most promising approaches to food processing (Xanthakis et al., 2013; He et al., 2013). One study involved reducing the thawing time of pork tenderloin under HVEF treatment (He et al., 2013). In those previous studies, DC HVEF was applied for electric thawing. Hitherto, however, no comparison has been made of the effects of DC and AC HVEF in electro-freezing. Accordingly, in the present study, these two types of HVEF were analyzed in electro-freezing. The aim of this research was to make a systematic investigation of the optimal HVEF and voltage conditions for freezing pork. 


\section{Materials and methods}

\subsection{Materials}

Fresh pork tenderloin was purchased from a MerryMart supermarket in Beijing, China. The selected meat was light cherry red in color. The moisture content was $71.54 \pm 0.47 \%$ according to direct drying method. The protein content was $20.3 \pm$ $0.7 \%$ based on Kjeldahl method. After purchase, the meat was sealed in plastic bags to prevent the oxidation of proteins, such as sarcoplasmic proteins (which are associated with meat color) and myofibrillar proteins (which have an impact on water-holding capacity ([WHC]). They were then transported in a polystyrene box containing ice bags so as to avoid temperature fluctuations. The fresh meat was cut into cuboids $\left(50 \times 50 \times 10 \mathrm{~mm}^{3}\right)$ and stored in a $4^{\circ} \mathrm{C}$ refrigerator $(B C D-285 \mathrm{WNMVS}$; Samsung, Suzhou, China). The storage time of pork was less than $24 \mathrm{~h}$. All the chemicals used were of analytic grade.

\subsection{HVEF freezing experiment and temperature-monitoring system}

The experimental system used was designed for this study (Fig. 1). Briefly, it comprised a miniature refrigerator, a DC voltage generator (DW-P303-1ACCC, Tianjin Dongwen High Voltage Power Supply Company, Tianjin, China), an AC voltage generator, a treatment chamber, a multiple point-to-plate electrode, and a real-time temperature- and humidity-monitoring system. The electrode used in this study was different from the one used in the study by the Alain Le-Bail' team 
(Orlowska et al., 2009; Xanthakis et al., 2013). The refrigerator consisted of a condensing unit (2HES-1, Bitzer Compressors [Beijing] Ltd., Beijing, China), an evaporator (DD15, Beijing Kaidi Refrigeration Equipment Co., Ltd., Beijing, China), a solenoid valve (Danfoss [China] Co., Ltd., Tianjin, China), and a pressure controller (Danfoss). The refrigerator was $1700 \mathrm{~mm}$ long, $1200 \mathrm{~mm}$ wide, and $2200 \mathrm{~mm}$ high. The refrigerator body was made of polyurethane with a thickness of $100 \mathrm{~mm}$, which conforms to Chinese industrial standards (JBT 6527-2006). The temperature could be adjusted from $+8^{\circ}$ to $-25^{\circ} \mathrm{C}$ with an accuracy of $\pm 2^{\circ} \mathrm{C}$. In a preliminary experiment, it was determined that the refrigerator cooled at a rate of $1.1^{\circ} \mathrm{C} / \mathrm{min}$ when the temperature was set to $-20^{\circ} \mathrm{C}$. This rate is similar to one reported previously (Xanthakis et al., 2013).

The output voltage could be adjusted in the range of $0-10 \mathrm{kV}$ using the DC voltage generator. The virtual voltage output in the range of $0-10 \mathrm{kV}$ could be adjusted using an AC voltage-regulation system, which consisted of a transformer (TDM2.5/60; Beijing Transformer Company, Beijing, China) and a voltmeter (JGM-100; Beijing Transformer Company). To avoid electrical conduction, the treatment chamber was constructed of wood and acrylic board. The upper electrode contained 81 needles (70 $\mathrm{mm}$ long, $1 \mathrm{~mm}$ in diameter; $20 \mathrm{~mm}$ between any two needles). The temperature- and humidity-monitoring system contained a midi logger (GL220, Graphtec, Yokohama, Japan), a T-type thermocouple, and a humidity-voltage conversion module (B-530, Graphtec). Thermocouples were also used in the electromagnetic field environment by Lyng et al. (2005) and Yarmand et al. (2013). During measurements, the temperature 
change of the samples was recorded per minute using the data logger. The whole experimental system was set up in a basement with almost constant temperature $\left(17.63^{\circ} \pm 0.43^{\circ} \mathrm{C}\right)$ and humidity $(15.25 \% \pm 0.63 \%)$.

\subsection{HVEF freezing process}

Two systems were studied in this work, the first of which was used to compare the different freezing processes of almost pure substances both with and without the application of a DC or AC HVEF. With system 2, the experiments used a single type of HVEF selected from the optimal results of the system 1 experiments. With system $1,10 \mathrm{~mL}$ DW was placed in an aluminum crucible (30 $\mathrm{mm}$ long, $50 \mathrm{~mm}$ in diameter). Temperature sensors were immersed in the water for each trial. With system 2, cuboid samples $(50 \times 50 \times 10 \mathrm{~mm})$ of fresh pork tenderloin were put on aluminum foil. The temperature sensors were placed at the geometric center of the samples. Since nucleation is a stochastic, spontaneous process, at least five samples were measured for both systems under the two types of voltage conditions. In addition, new samples of DW and meat were used in each experiment.

The initial temperatures of the DW and meat samples were maintained at almost the same level among each group in each experiment. The AC or DC voltage was applied at the same time upon initiation of cooling the samples to less than $-15^{\circ} \mathrm{C}$. The voltages studied in the two systems were as follows: $0,4,6,8$, and $10 \mathrm{kV}$. For AC, the voltage's true value was equal to the DC voltage that could produce the same power consumption at the same resistance. After freezing the frozen samples were thawed 
under ambient conditions $\left(20^{\circ} \pm 1^{\circ} \mathrm{C}\right.$ for nearly 60 minutes $)$ before analysis.

\subsection{Nuclear magnetic resonance spectroscopy}

The nuclear magnetic resonance (NMR) proton relaxation measurements of the meat samples were performed at low-field NMR (LF-NMR). The meat was cut into cuboids $(15 \times 15 \times 10 \mathrm{~mm} ; 2.617 \pm 0.170 \mathrm{~g})$. Then, the samples were individually wrapped in parafilm membrane and put into a flat-bottomed cylindrical glass tube (200 $\mathrm{mm}$ long, $25 \mathrm{~mm}$ in diameter). The LF-NMR experiments were carried out on a low-resolution spectrometer (PQ001, Newman, Shanghai, China). The Carr-Purcell-Meiboom-Gill pulse sequence was adopted to measure the transverse relaxation time $\left(T_{2}\right)$ between 0 and $10,000 \mathrm{~ms}$. The separations between the $90^{\circ}$ and $180^{\circ}$ pulses were 4.00 and $9.00 \mu$ s, respectively, and 247,200 data points were collected. Eight scans were made with a 3000-ms waiting time. The peak areas that represented the distribution of different water populations were transformed into percentages. The moisture content was calculated using the peak area as a percentage of the sum of all peaks. The NMR measurements were performed at ambient temperature.

\subsection{Differential scanning calorimetry}

The meat samples were examined using differential scanning calorimetry (DSC) with no extraction or purification. The DSC analyses were performed on a DSC-60 Differential Scanning Calorimeter (Shimadzu, Kyoto, Japan). Pork weighing 3-5 mg 
were used for the DSC. The heating rate was $10^{\circ} \mathrm{C} / \mathrm{min}$, and the final temperature for the DSC scans was $110^{\circ} \mathrm{C}$. An empty crucible was used as a reference. The three maximum temperatures of the peaks $\left(T_{\text {peak }}\right)$ and denaturation enthalpy $(D H)$ were used to determine the characteristics of the denaturation of the pork proteins. The levels of $D H$ of peak $1\left(D H_{\text {peak } 1}\right)$, peak $2\left(D H_{\text {peak } 2}\right)$, peak $3\left(D H_{\text {peak } 3}\right)$, and peak $1+$ peak 2 $\left(\mathrm{DH}_{\text {peak } 1+2}\right)$ were estimated.

\subsection{Quality parameters of pork tenderloin}

\subsubsection{Color measurement}

The color of the frozen-thawed pork tenderloin samples was determined using a CR-300 chromameter (Konica Minolta Sensing, Inc., Tokyo, Japan). CIE $L^{*}$ (lightness), $a^{*}$ (redness), and $b^{*}$ (yellowness) values were recorded. The chroma $(C)$, total color difference $(\Delta E)$, and whiteness were calculated using the following equations (Dai et al., 2013; Liu et al., 2013):

$$
\begin{aligned}
& C=\sqrt{a^{* 2}+b^{* 2}} \\
& \Delta E=\left[\left(L^{*}-L_{0}^{*}\right)^{2}+\left(a^{*}-a_{0}^{*}\right)^{2}+\left(b^{*}-b_{0}^{*}\right)^{2}\right]^{\frac{1}{2}}=\left[\left(\Delta L^{*}\right)^{2}+\left(\Delta a^{*}\right)^{2}+\left(\Delta b^{*}\right)^{2}\right]^{\frac{1}{2}} \\
& \text { Whiteness }=100-\left[\left(100-L^{*}\right)^{2}+a^{* 2}+b^{* 2}\right]^{\frac{1}{2}}
\end{aligned}
$$

\subsection{2 $\mathrm{pH}$ and expressible moisture}

The buffer $(\mathrm{pH}$ 7.0) used for $\mathrm{pH}$ measurement consisted of $5 \mathrm{mM}$ sodium iodoacetate and $150 \mathrm{mM}$ potassium chloride. Minced pork tenderloin (2.5 g) was homogenized with $25 \mathrm{~mL}$ cold buffer using a ceramic mortar. Then, the $\mathrm{pH}$ was 
measured using a pH meter (Orion 5-star, Thermo Electron Corporation, Lexington, Kentucky, USA) (Liu et al., 2013).

The expressible moisture (EM) was determined by the method of Dai et al. (2013), with some modifications. Briefly, the pork tenderloin samples used here were $50 \times 10$ $\times 10 \mathrm{~mm}$ in size and weighed $9.24 \pm 0.92 \mathrm{~g}$. They were centrifuged at $2500 \mathrm{~g}$ for 20 $\min$ at $4{ }^{\circ} \mathrm{C}$. $E M$ was calculated as the percentage of moisture loss after centrifugation relative to the initial weight of meat.

\subsection{Microscopic analysis}

\subsubsection{Scanning electron microscopy}

Meat samples that were frozen with or without being subjected to a $10-\mathrm{kV}$ DC HVEF were prepared for microstructural analysis. A scanning electron microscope (SEM; Quanta 200F, FEI, Hillsboro, OR, USA) at Tsinghua University was used. The frozen samples were lyophilized, pasted onto the conducting resin, and coated with gold for $90 \mathrm{~s}$. The high-vacuum mode was chosen with 130-Pa chamber pressure. Unlike the $150 \times$ magnification used for observing the microstructural change of duck meat (Li et al., 2013), the samples were observed at 100× magnification by means of an accelerating voltage of $15 \mathrm{kV}$. In addition, the micro-graphs were also taken at magnification of $4500 \times$ to observe the arrangement of myofibril.

\subsubsection{Light microscopy}

The fixation method for light microscopy was in accordance with the method 
reported by Liu et al. (2013). Fresh and frozen meat samples $(10 \times 10 \times 10 \mathrm{~mm})$, which had been cut perpendicular and parallel to the muscle fibers, were fixed with $3 \%$ glutaraldehyde in sodium phosphate buffer $(0.1 \mathrm{M}, \mathrm{pH} 7.4)$ for $48 \mathrm{~h}$. The samples were then dehydrated at $4^{\circ} \mathrm{C}$ with a graded series of ethanol solutions $(70 \%-100 \%$, v/v) using a dehydrator (Asp200s, Leica, Wetzlar, Germany). Thereupon, the tissues were immersed in xylene to make them transparent. Wax (39601095, Leica) was used to soak the meat to ensure fixation of the meat tissue. The sample was then embedded in paraffin by means of an embedding station (EG1150H, Leica) to facilitate slicing. Slices were cut using a microtome (CM3050S, Leica) and subjected to hematoxylin and eosin (HE; ST5020, Leica), followed by observation at 200× magnification. The imageJ 1.46r (Wayne Rasband, National Institutes of Health, USA) was used to calculated the area of both extra- and intracellular spaces which were not stained by HE. For the extra- and intracellular spaces, they contained the voids caused by ice crystal. So the total area of ice crystal could be calculated by the following equation:

Total area of ice crystal $(\%)=S_{\text {frozen }}-S_{\text {fresh }}$

Where $S_{\text {frozen }}$ is the area of both extra- and intracellular spaces which were not stained by HE in frozen pork tenderloin, while the $S_{\text {fresh }}$ is the area of both extra- and intracellular spaces which were not stained by HE in fresh pork tenderloin.

\subsection{Data analysis}

The results were statistically analyzed using SPSS 20.0 (IBM Corporation, Armonk, NY, USA). The least significant difference procedure and Duncan's test were used to compare mean values, with significance set at $P<0.05$. 


\section{Results and Discussion}

\subsection{Freezing behavior of DW and pork tenderloin}

The processes of freezing DW and pork tenderloin samples are shown in Fig. 2. The DW frozen in the aluminum crucible exhibited supercooling before starting to freeze, as has been widely reported elsewhere (Kiani et al., 2011). The $T_{\mathrm{n}}$ of DW is consistent with a previously published finding of water samples being nucleated at $-7.4^{\circ} \pm 2.4^{\circ} \mathrm{C}$ (Kiani et al., 2011). The $T_{\mathrm{m}}$ of pork tenderloin was similar to those of Farouk et al (2013) (Table 2). The range of initial freezing points of beef measured by them was $-0.9^{\circ} \mathrm{C}$ to $-1.5^{\circ} \mathrm{C}$. Moreover, the $T_{\mathrm{m}}$ of pork tenderloin measured in this study is in the range of the freezing points introduced by Stonehouse \& Evans (2015). From a comparison of the two typical curves during the course of the freezing experiment, it was difficult to identify a $T_{\mathrm{n}}$ point for the pork tenderloin. The curve of pork tenderloin internal temperature was similar with that of lamb (Muela et al., 2012). The phase transition time (crystallization time, $t_{\mathrm{c}}$ ) was calculated in this paper as the time span between initial freezing point and reaching a temperature $1.5^{\circ} \mathrm{C}$ below the corresponding initial freezing point. Meat is a complex matrix of water, fat, and protein, whereby the water molecules bind to the proteins and other components. Water is a major component of food, and so studying the freezing of DW is vital toward understanding the freezing process in meat (Kiani \& Sun, 2011). 
It was found that AC HVEF freezing and DC HVEF freezing led to notable shifts in $T_{\mathrm{n}}$ of DW, respectively. For AC, the $T_{\mathrm{n}}$ of DW treated with freezing at $0,4,6,8$, and $10 \mathrm{kV}$ was $-5.3^{\circ} \pm 0.6^{\circ} \mathrm{C},-3.7^{\circ} \pm 1.4^{\circ} \mathrm{C},-4.7^{\circ} \pm 1.6^{\circ} \mathrm{C},-5.3^{\circ} \pm 0.8^{\circ} \mathrm{C}$ and $-3.7^{\circ} \pm$ $0.8^{\circ} \mathrm{C}$. There were significant differences of $T_{\mathrm{n}}$ between the $\mathrm{DW}$ treated without AC HVEF and the ones treated with $4 \mathrm{kV}$ or $10 \mathrm{kV}$ AC HVEF $(P<0.05)$. Orlowska et al. (2009) also reported the phenomenon of $T_{\mathrm{n}}$ becoming almost 1.5 times higher as a result of electro-freezing. The extent of supercooling of the DC HVEF-assisted freezing group in Table 1 was smaller than that of the AC HVEF-assisted one. Moreover, Pearson correlation coefficient was calculated to quantify the association between $t_{\mathrm{c}}$ and the treatment voltage. The correlation coefficients were $0.627^{* *}$ (a 2-tailed significant correlation at the 0.01 level is indicated by **). So the time required for complete solidification of DW increased with the treatment voltage, which was also consistent with the result by Orlowska et al. (2009). DC HVEF has a more beneficial effect on nucleus formation at relatively high temperatures than AC HVEF, and so DC treatment was selected for further study using the meat model.

\subsection{Freezing behavior of meat with DC}

The temperature profiles of pork tenderloin showed a region of supercooling in a very few cases. In the averaged data sets, the effect of supercooling for the meat samples was minimal. As shown in Table 2, there were not significant differences of the crystallization temperature for each group. It was also determined in this study that the application of a DC current at $4,6,8$ and $10 \mathrm{kV}$ did not prolong the 
phase-transition time. As the moisture condensation was very serious in the miniature refrigerator, the highest voltage used in this study was $10 \mathrm{kV}$ to protect the voltage generator. Although there are several studies regarding on freezing pork (Anese et al., 2012; Xanthakis et al., 2013, 2014; Choi et al., 2016), unfortunately, few studies have examined the process of freezing pork using HVEF with prick electrode. This type of electrode was effective in shortening the thawing time of pork tenderloin with a positive effect to decrease the time in the zone of maximum ice crystal formation (He et al., 2013).

According to the power equation, the DC HVEF energy consumption levels at 10 $\mathrm{kV}$ for thawing pork tenderloin were $0.4 \pm 0.1 \mathrm{~W}$; that level compares favorably with the power consumption of a $3 \mathrm{~kW}$ refrigerator. DC HVEF-assisted freezing is therefore an energy-efficient method. Freezing of meat are related with many important qualities alteration, such as WHC and meat colour. Consequently, the indicators will be discussed in the following sections.

\subsection{Relaxation of water in meat}

Low-resolution NMR spectroscopy has been considered suitable for measuring the mobility of water molecules in a complex matrix (Huang et al., 2011). It is used to study the water distribution and mobility in meat and meat products (Zheng et al., 2015). In addition, it has been demonstrated that NMR parameters are connected with the quality of meat in terms of drip loss and WHC (Gudjónsdóttir et al., 2011; Li et al., 2012). It has been reported that there are three water populations in pork: water 
closely associated with macromolecules (e.g., proteins), at 1-3 ms; water in myofibrils, at 40-80 ms; and water outside myofibrils, at 200-400 ms (Bertram \& Andersen, 2007). The various groups of water molecules are evident in the $T_{2}$ distribution (Fig. 3). The peaks of relaxation times represent the three components of water: bound water, immobilized water, and free water, labeled "peak 1," "peak 2," "peak 3," respectively. Among them, immobilized water and free water, have been studied in many LF-NMR studies (Aursand, Veliyulin, Böcker, Ofstad, \& Erikson, 2008; Zheng et al., 2015). The classification of the $T_{2}$ relaxation times of water into these populations in fresh pork tenderloin is shown in Fig. 3A. Our $T_{2}$ relaxation time data are consistent with those of Bertram and Andersen (2007). In our preliminary experiment, it was demonstrated that freezing led to shorter $T_{2}$ relaxation times; the relative amount of water in each population also changed markedly compared with that in fresh pork tenderloin. Thus, the frozen meat was thawed and used for NMR data acquisition to compare the differences between fresh and frozen-thawed samples (Fig. 3). In addition, the relaxation times and relaxation populations were both significantly affected by the treatment method, e.g., brine salting and pressure/thermal treatments. Hence, both of these characteristics should be studied.

The degree of freedom of molecular water is associated with $T_{2}$. Specifically, an increase in water mobility is associated with a shift toward longer $T_{2}$ relaxation times. The $T_{2}$ relaxation times of molecular water in pork tenderloin subjected to different DC HVEF-assisted freezing treatments are presented in Fig. 3 and Table 3. There were significant differences in the $T_{2}$ of peak 1 between fresh and defrosted meat $(P<$ 
0.05). Briefly, for the defrosted meat, the shifts in $T_{2}$ indicated that the bound water became freer. In addition, the decrease in $T_{2}$ of peak 3 suggested that the degree of freedom of free water was reduced. The change in $T_{2}$ would appear to have been caused by the freezing and thawing process. HVEF had little impact on the $T_{2}$ value.

The peaks' area, or the proton population (PP), refers to the relative quantity of the water population in pork tenderloin (Table 3). It was believed that the lower population of peak 3, the lower the centrifugation loss (Zheng et al., 2015). Except for the PP (\%) of peak 3 in fresh meat, the PP (\%) of peak 3 in meat subjected to $10 \mathrm{kV}$ was the smallest. Moreover, Sánchez-Alonso et al (2012) reported that the WHC decreased with an increase in the PP (\%) of peak 3 and a decrease in the PP (\%) of peak 2 during storage. So the WHC of pork tenderloin treated with $10 \mathrm{kV} \mathrm{HVEF}$ freezing was better than other groups. As we know, the centrifugation loss is related with WHC. Moreover, there were significant differences for the population of peak 2 $(P<0.05)$. Since the PP $(\%)$ of peak 2 in meat subjected to $10 \mathrm{kV}$ freezing was the closest to that of peak 2 in fresh meat, meat quality (e.g., WHC) with $10 \mathrm{kV}$ freezing should be superior to that of the other groups. In contrast, the PP (\%) of peak 2 and peak 3 for defrosted meat that had not been frozen under HVEF conditions was the smallest and largest among the groups, respectively, which illustrates that the freezing process significantly influenced the content of the three moisture components in meat and would have negatively affected its quality. Except with $8 \mathrm{kV}$ freezing, the PP (\%) of peak 3 gradually decreased with increasing voltage. The water molecules were reoriented by the HVEF in the freezing process, which would have affected the peaks' 
area. In addition, the electrostatic repulsion of the myofibrillar proteins as a result of the HVEF could have changed the water mobility and PP (\%) of peak 2 and peak 3.

\subsection{Denaturation of myosin related to WHC}

The thermograms of pork tenderloin appear in Fig. 4. The denaturation of myosin heads, myosin tails/sarcoplasmic proteins, and actin are represented by the three endothermal peaks. There were significant differences in $T_{\text {peak1 }}$ between fresh and frozen-thawed pork tenderloin $(P<0.05$; Table 4$)$. This indicates that structural changes in myosin occurred during the freezing and thawing of the meat. However, the myosin denaturation of meat frozen without being subjected to a $10 \mathrm{kV}$ HVEF was more severe than that of HVEF-assisted frozen meat. Myofibrillar proteins, including myosin, are known to be associated with WHC in muscle or meat. Meat quality is poor when myosin ATPase activity has been suppressed. Therefore, meat treated by $10 \mathrm{kV}$ HVEF had superior quality to that not subjected to HVEF. In addition, no significant differences in $T_{\text {peak2 }}$ and $T_{\text {peak3 }}$ were observed among the samples in this study. Thus, myosin was shown to be more sensitive to a low-freezing-temperature environment than sarcoplasmic proteins or actin.

The $D H$ of fresh meat was more pronounced than that of the control group (Ck) and groups by $10 \mathrm{kV}$, which mainly indicated that fresh pork proteins were the most stable; the $\mathrm{DH}$ of the $\mathrm{Ck}$ was the smallest (Table 4). In addition, sarcoplasmic proteins also play an important role in determining WHC of meat (Marcos et al., 2010). There were significant differences between the $\mathrm{DH}_{\text {peak2 }}$ of $\mathrm{Ck}$ and $10 \mathrm{kV}$ HVEF assisted freezing 
groups $(P<0.05)$, which indicated better WHC of groups assisted by $10 \mathrm{kV}$ than that of Ck.

\subsection{Color, $\mathrm{pH}$, and EM}

Color parameters including $L^{*}, a^{*}, b^{*}, C$, and total color difference $(\Delta E)$ are important indicators of meat quality and market value; they appear in Table 5. Fresh pork exhibited higher $L^{*}$ values than meat subjected to freezing and thawing $(P<$ 0.05; Table 5). In addition, the meat samples became red during the freezing and thawing process, especially in the $\mathrm{Ck}$. As well as single color parameters, meat color can be estimated using $\Delta E$. The appearance of meat is considered to have modified when the value of $\Delta E$ is at least 10 (Marcos et al., 2010). In the present study, the values of $\Delta E$ of the $\mathrm{Ck}$ and meat samples treated by $10 \mathrm{kV}$ were both less than 10 ; thus, meat color was not considered to have changed significantly. Pearson correlation coefficient was calculated to quantify the association between $E M$ and $L^{*}$ values. The correlation coefficients were $-0.79 *$ (a 2-tailed significant correlation at the 0.05 level is indicated by *). So the WHC is closely correlated with the colour of pork tenderloin. The flesh colour of pork tenderloin should be associated with myoglobin, heme-based pigments and tissue structure (Mancini \& Hunt, 2005).

There were no significant differences in $\mathrm{pH}$ between the fresh and the one treated by $10 \mathrm{kV}$ HVEF (Table 5). The $\mathrm{pH}$ in the $\mathrm{Ck}$ was smaller than in the other groups, which may have been caused by oxidative rancidity. Finally, although the mean $E M$ of electro-freezing group by $10 \mathrm{kV}$ HVEF did not show a significant decrease compared 
with the one of $\mathrm{Ck}$, at the level of $10 \mathrm{kV}$ the $E M$ showed around $6 \%$ decrease of their average $E M$ compared to the $\mathrm{Ck}$, which is consistent with our NMR and DSC data. The degradation of parameters (e.g., $E M$ and texture) for pork tenderloin is also closely connected with the ice crystal in the meat. So the destructive effects caused by ice crystal were observed in the following section.

\subsection{Microscopic observation}

The surface and cuts perpendicular to the direction of the fibers in the samples are illustrated in Fig. 5. At the surface of meat subjected to $10 \mathrm{kV} \mathrm{DC}$ and freezing (Fig. 5B), the voids were smaller than upon freezing without electrical treatment (Fig. 5A). The surfaces of frozen and electrically treated samples were thus smoother than those of ordinary frozen samples. Regarding the interior of the meat samples, the voids were smaller in the group treated by $10 \mathrm{kV} \mathrm{DC}$ (Fig. 5B) than in the group without electrical treatment (Fig. 5A). It is assumed that the size of the ice crystals that develop during the freezing process reflects the size of the voids. Therefore, our results are consistent with the conclusion of Xanthakis et al. (2013), whereby morphological changes could be caused by ice crystals. The size of ice crystal is an important factor related to muscle deterioration, because the formation of large ice crystals should lead to an extensive mechanical damage; as a consequence, interaction of cellular components (e.g., lipids and proteins) with enzymes leads to protein denaturation and lipid degradation. Moreover, the myofibril could be seen clearly for the $4500 \times$ magnification. Compared to freezing without electrical treatment, the 
freezing assisted by $10 \mathrm{kV}$ HVEF could lead to dense arrangement of myofibril (Fig. 5B). Thus, the destructive effects of freezing could be minimized by combination with $10 \mathrm{kV}$ DC treatment.

The cross and longitudinal sections of the samples stained with HE are shown in Fig. 6. For fresh meat (Fig. 6A), the typical shape of the cells was well preserved, and the muscle fibers were tightly attached to one another. With the frozen-thawed meat (Fig. 6B, C), the space between the muscle fibers had become larger than with fresh meat. Moreover, there was greater damage to the cells in frozen meat, which may have been caused by ice crystals (Fig. 6B). In a comparison of cross sections of frozen-thawed meat, the cells in the freezing group assisted by $10 \mathrm{kV} \mathrm{DC}$ were more intact than those not subjected to electrical treatment. The microstructural damage of electro-frozen pork tenderloin was thus minimal compared with meat subjected to ordinary freezing. The area of both extra- and intracellular spaces which were not stained by HE is shown in Fig. 7. Based on the area results, the total area of ice crystal for the cross sections of pork tenderloin by ordinary freezing and freezing with $10 \mathrm{kV}$ HVEF was $13.77 \pm 0.93 \%$ and $1.37 \pm 0.61 \%$, respectively. There were significant differences of total area of ice crystal for the two freezing method $(P<0.05)$. Hence, freezing pork tenderloin with $10 \mathrm{kV}$ DC should offer advantages over conventional freezing.

\section{Conclusions}

In this study, supercooling was not evident in the pork tenderloin samples; however, 
it did occur during the freezing of DW. The $T_{\mathrm{n}}$ of DW was affected by both AC and DC HVEF; however, $T_{\mathrm{n}}$ changed more with DC than with AC treatment. It was also observed that the phase-transition time of DW increased with the treatment voltage, while the $t_{\mathrm{c}}$ of pork tenderloin did not increase with the treatment voltage. Moreover, the power consumption of DC HVEF was little, suggesting that HVEF is a promising application with frozen food.

Freezing in combination with exposure to a $10 \mathrm{kV}$ DC environment maintained the water properties at levels similar to those in fresh pork tenderloin; it also led to smaller ice crystals than ordinary freezing treatments. Furthermore, this approach decreased protein denaturation. The meat quality indicators, including color, $\mathrm{pH}$, and WHC, were closer to those of fresh pork tenderloin after the freezing assisted by 10 $\mathrm{kV}$ treatment than after freezing without HVEF. It is therefore concluded that $10 \mathrm{kV}$ DC assisted freezing of pork tenderloin offers quality advantages over conventional air freezing.

\section{Acknowledgements}

This study was supported by the National Science Foundation of China (NSFC), "Study on the characteristics and mechanism of freezing and thawing of meat under high-voltage electrostatic field" (No. 31571908).

\section{References}

Aursand, I. G., Veliyulin, E., Böcker, U., Ofstad, R., Rustad, T., \& Erikson, U. (2008). 
Water and salt distribution in Atlantic salmon (Salmo salar) studied by low-field $1 \mathrm{H}$ NMR, $1 \mathrm{H}$ and $23 \mathrm{Na}$ MRI and light microscopy: effects of raw material quality and brine salting. Journal of agricultural and food chemistry, 57(1), 46-54.

Anese, M., Manzocco, L., Panozzo, A., Beraldo, P., Foschia, M., \& Nicoli, M. C. (2012). Effect of radiofrequency assisted freezing on meat microstructure and quality. Food Research International, 46(1), 50-54.

Bertram, H. C., \& Andersen, H. J. (2007). NMR and the water-holding issue of pork. Journal of Animal Breeding and Genetics, 124(s1), 35-42.

Choi, M. J., Min, S. G., \& Hong, G. P. (2016). Effects of pressure-shift freezing conditions on the quality characteristics and histological changes of pork. LWT-Food Science and Technology, 67, 194-199.

Dai, Y., Miao, J., Yuan, S. Z., Liu, Y., Li, X. M., \& Dai, R. T. (2013). Colour and sarcoplasmic protein evaluation of pork following water bath and ohmic cooking. Meat Science, 93(4), 898-905.

Farouk, M. M., Kemp, R. M., Cartwright, S., \& North, M. (2013). The initial freezing point temperature of beef rises with the rise in $\mathrm{pH}$ : A short communication. Meat science, 94(1), 121-124.

Gudjónsdóttir, M., Lauzon, H. L., Magnússon, H., Sveinsdóttir, K., Arason, S., Martinsdóttir, E., \& Rustad, T. (2011). Low field nuclear magnetic resonance on the effect of salt and modified atmosphere packaging on cod (Gadus morhua) during superchilled storage. Food Research International, 44(1), 241-249.

Huang, Y., Davies, E., \& Lillford, P. (2011). Effect of Solutes and Matrix Structure on 
Water Mobility in Glycerol-Agar-Water Gel Systems: A Nuclear Magnetic Resonance Approach. Journal of Agricultural and Food Chemistry, 59(8), 4078-4087.

Hu, F., Sun, D. W., Gao, W., Zhang, Z., Zeng, X., \& Han, Z. (2013). Effects of pre-existing bubbles on ice nucleation and crystallization during ultrasound-assisted freezing of water and sucrose solution. Innovative Food Science \& Emerging Technologies, 20, 161-166.

He, X., Liu, R., Nirasawa, S., Zheng, D., \& Liu, H. (2013). Effect of high voltage electrostatic field treatment on thawing characteristics and post-thawing quality of frozen pork tenderloin meat. Journal of Food Engineering, 115(2), 245-250.

Kiani, H., Zhang, Z., Delgado, A., \& Sun, D. W. (2011). Ultrasound assisted nucleation of some liquid and solid model foods during freezing. Food Research International, 2011, 44(9), 2915-2921.

Kiani, H., \& Sun, D. W. (2011). Water crystallization and its importance to freezing of foods: A review. Trends in Food Science \& Technology, 22(8), 407-426.

Li, B., \& Sun, D. W. (2002). Novel methods for rapid freezing and thawing of foods-a review. Journal of Food Engineering, 54(3), 175-182.

Lyng, J. G., Zhang, L., \& Brunton, N. P. (2005). A survey of the dielectric properties of meats and ingredients used in meat product manufacture. Meat Science, 69(4), 589-602.

Li, C., Liu, D., Zhou, G., Xu, X., Qi, J., Shi, P., \& Xia, T. (2012). Meat quality and cooking attributes of thawed pork with different low field NMR $\mathrm{T}_{21}$. Meat science, 92(2), 79-83. 
Leygonie, C., Britz, T. J., \& Hoffman, L. C. (2012). Impact of freezing and thawing on the quality of meat: Review. Meat Science, 91(2), 93-98.

Liu, D., Liang, L., Xia, W., Regenstein, J. M., \& Zhou, P. (2013). Biochemical and physical changes of grass carp (Ctenopharyngodon idella) fillets stored at -3 and $0{ }^{\circ} \mathrm{C}$. Food Chemistry, 140(1), 105-114.

Li, C., Wang, D., Xu, W., Gao, F., \& Zhou, G. (2013). Effect of final cooked temperature on tenderness, protein solubility and microstructure of duck breast muscle. LWT-Food Science and Technology, 51(1), 266-274.

Marcos, B., Kerry, J. P., \& Mullen, A. M. (2010). High pressure induced changes on sarcoplasmic protein fraction and quality indicators. Meat Science, 85(1), 115-120.

Mancini, R. A., \& Hunt, M. (2005). Current research in meat color. Meat science, 71(1), 100-121.

Muela, E., Sañudo, C., Campo, M. M., Medel, I., \& Beltrán, J. A. (2012). Effect of freezing method and frozen storage duration on lamb sensory quality. Meat science, 90(1), 209-215.

Otero, L., \& Sanz, P. D. (2006). High-pressure-shift freezing: Main factors implied in the phase transition time. Journal of Food Engineering, 72(4), 354-363.

Orlowska, M., Havet, M., \& Le-Bail, A. (2009). Controlled ice nucleation under high voltage DC electrostatic field conditions. Food Research International, 42(7), 879-884.

Shevkunov, S. V., \& Vegiri, A. (2002). Electric field induced transitions in water clusters. Journal of Molecular Structure: THEOCHEM, 593(1), 19-32. 
Sánchez-Alonso, I., Martinez, I., Sánchez-Valencia, J., \& Careche, M. (2012). Estimation of freezing storage time and quality changes in hake (Merluccius merluccius, L.) by low field NMR. Food chemistry, 135(3), 1626-1634.

Stonehouse, G. G., \& Evans, J. A. (2015). The use of supercooling for fresh foods: A review. Journal of Food Engineering, 148, 74-79.

Wei, S., Xiaobin, X., Hong, Z., \& Chuanxiang, X. (2008). Effects of dipole polarization of water molecules on ice formation under an electrostatic field. Cryobiology, 56(1), 93-99.

Xanthakis, E., Havet, M., Chevallier, S., Abadie, J., \& Le-Bail, A. (2013). Effect of static electric field on ice crystal size reduction during freezing of pork meat. Innovative Food Science \& Emerging Technologies, 20, 115-120.

Xanthakis, E., Le-Bail, A., \& Ramaswamy, H. (2014). Development of an innovative microwave assisted food freezing process. Innovative Food Science \& Emerging Technologies, 26, 176-181.

Yarmand, M. S., Nikmaram, P., Djomeh, Z. E., \& Homayouni, A. (2013). Microstructural and mechanical properties of camel longissimus dorsi muscle during roasting, braising and microwave heating. Meat science, 95(2), 419-424.

Zheng, H., Xiong, G., Han, M., Deng, S., Xu, X., \& Zhou, G. (2015). High pressure/thermal combinations on texture and water holding capacity of chicken batters. Innovative Food Science \& Emerging Technologies, 30, 8-14. 


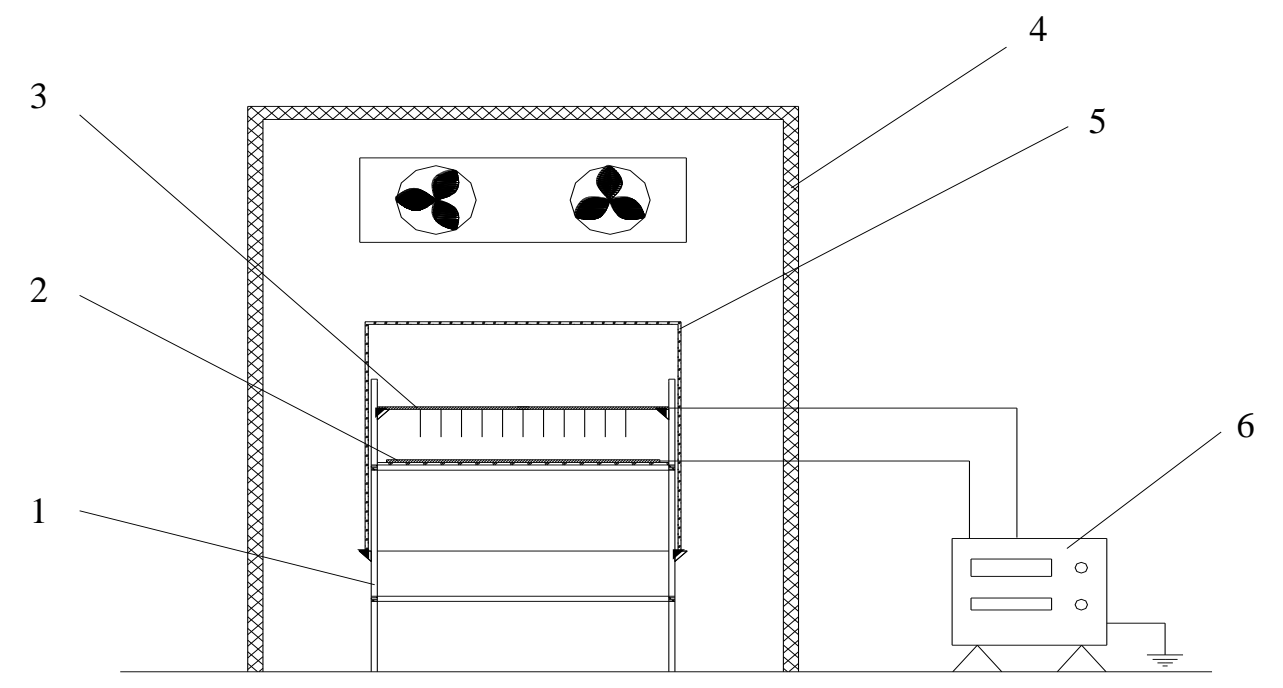

Fig. 1. Scheme of the experimental DC/AC HVEF refrigerator system used in the studies. 1. Treatment chamber. 2. Bottom plate. 3. Prick electrode. 4. Rerigerator body. 5. Cover. 6. Power supply. Sample (deionized water and pork tenderloin) were placed on the stainless steel plate. The voltage was applied between the upper needle-shaped electrode and the lower metallic surface. 
A

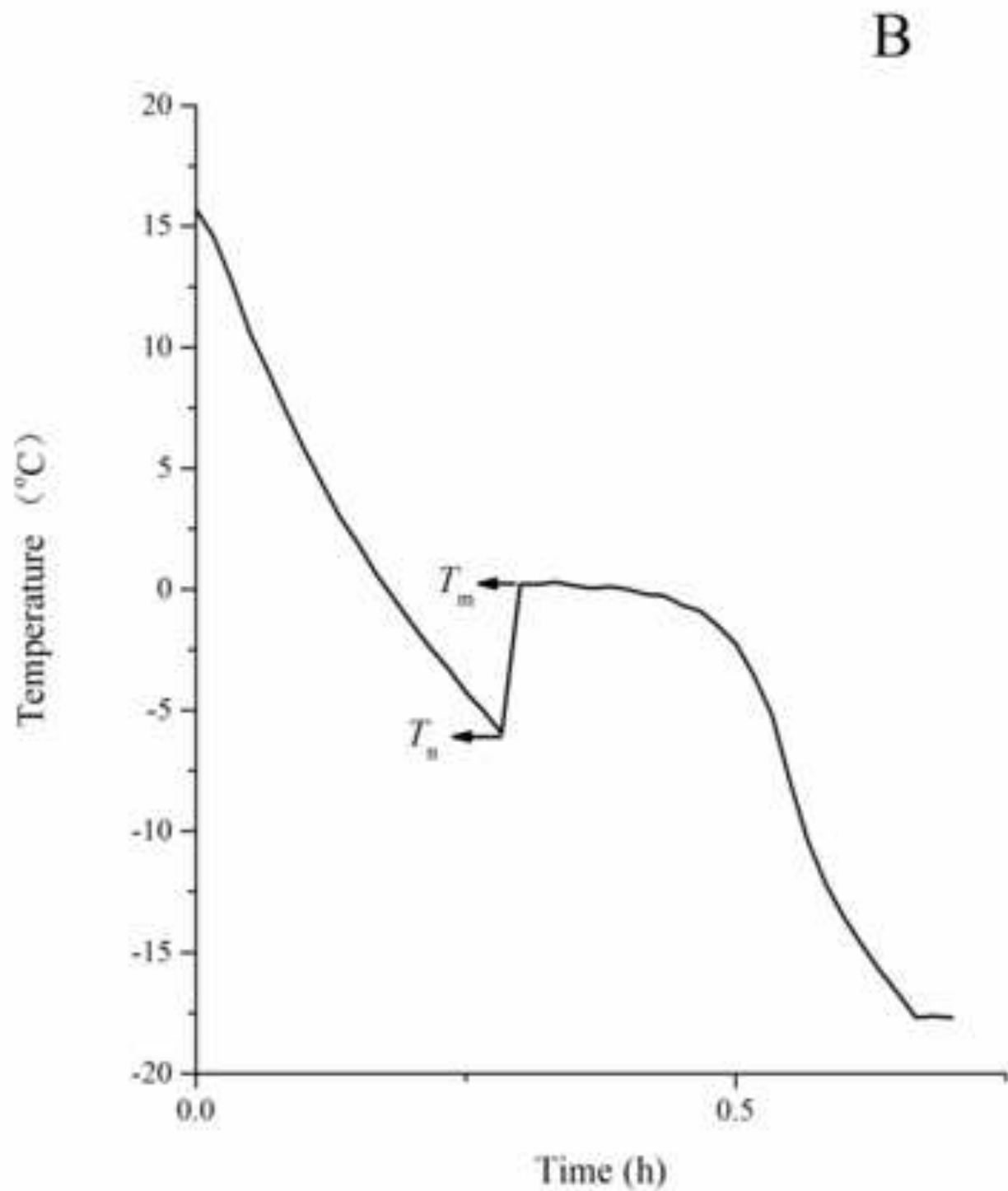

Fig. 2. Freezing curves of deionized water (A) and pork tenderloin (B).

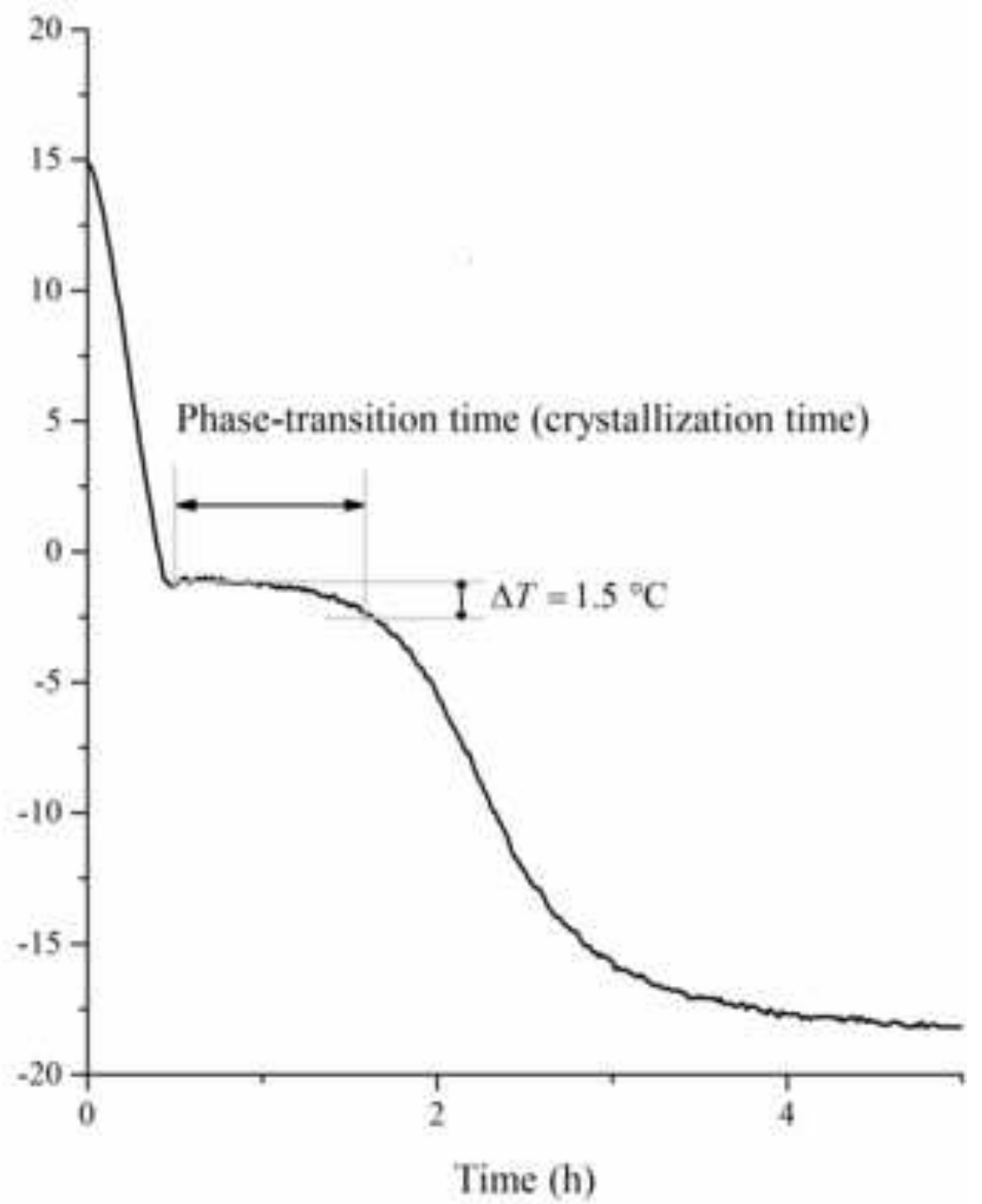



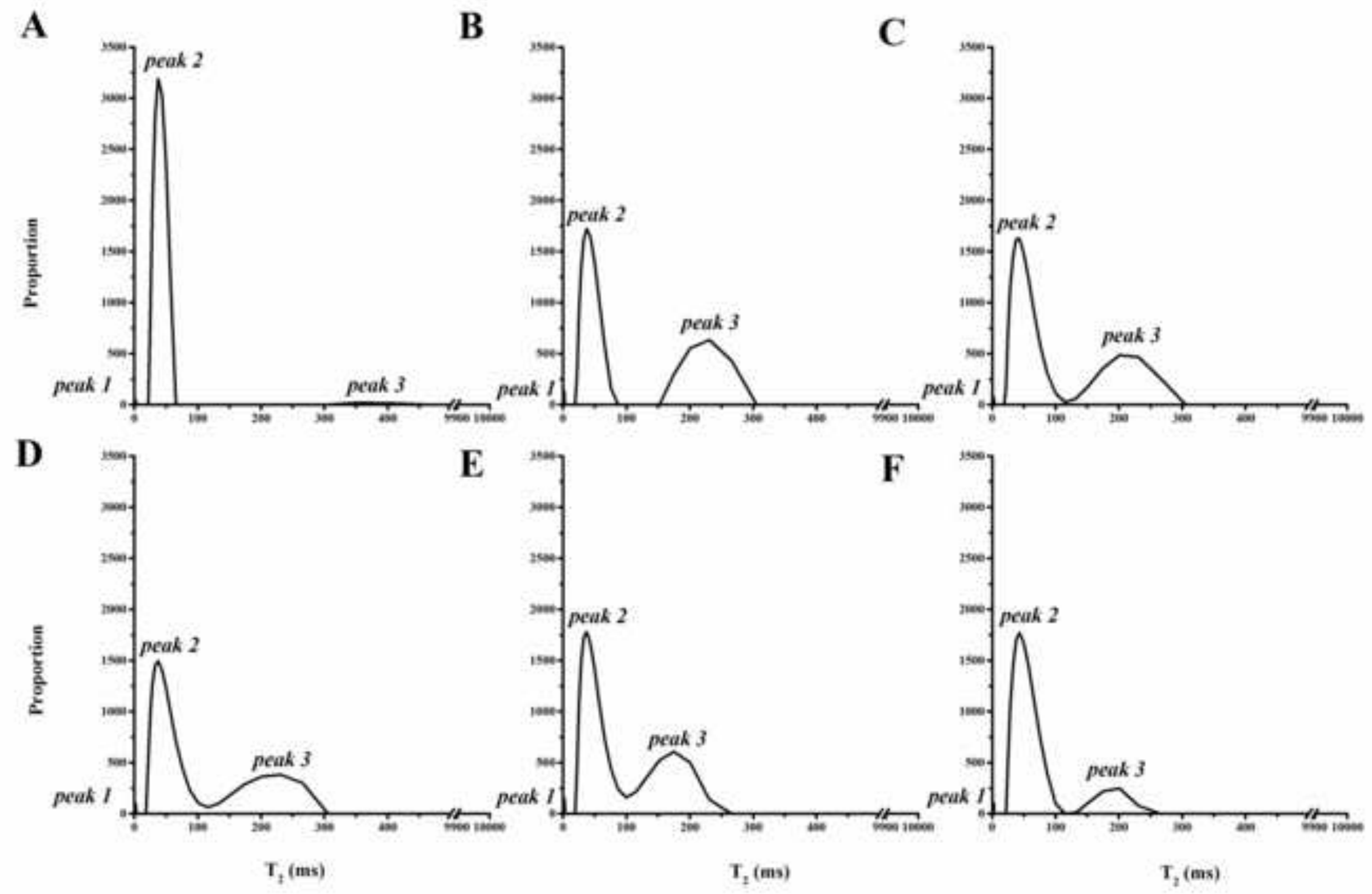

Fig. 3. CPMG spectra of pork tenderloin. Capital letters A, B, C, D, E, F denote fresh meat and the thawed meat which was freezed with $0 \mathrm{kV}, 4 \mathrm{kV}, 6 \mathrm{kV}, 8 \mathrm{kV}, 10 \mathrm{kV}$ DC HVEF before. 


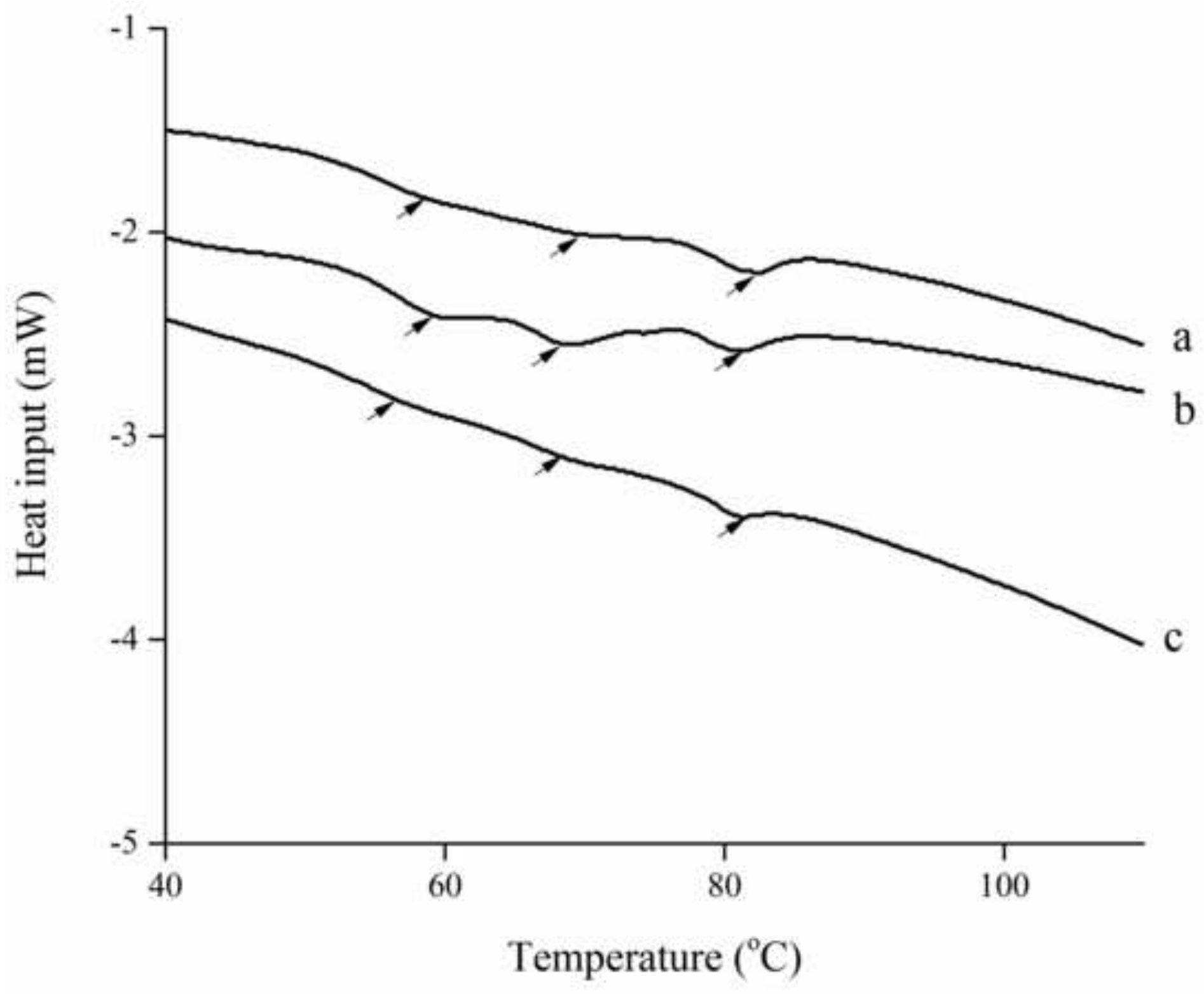

Fig. 4. Typical DSC thermograms from analysis of pork tenderloin. a) frozen pork with $10 \mathrm{kV}$ HVEF treatment, b) fresh pork, c) frozen pork. The arrow represents endothermic peaks. 
A
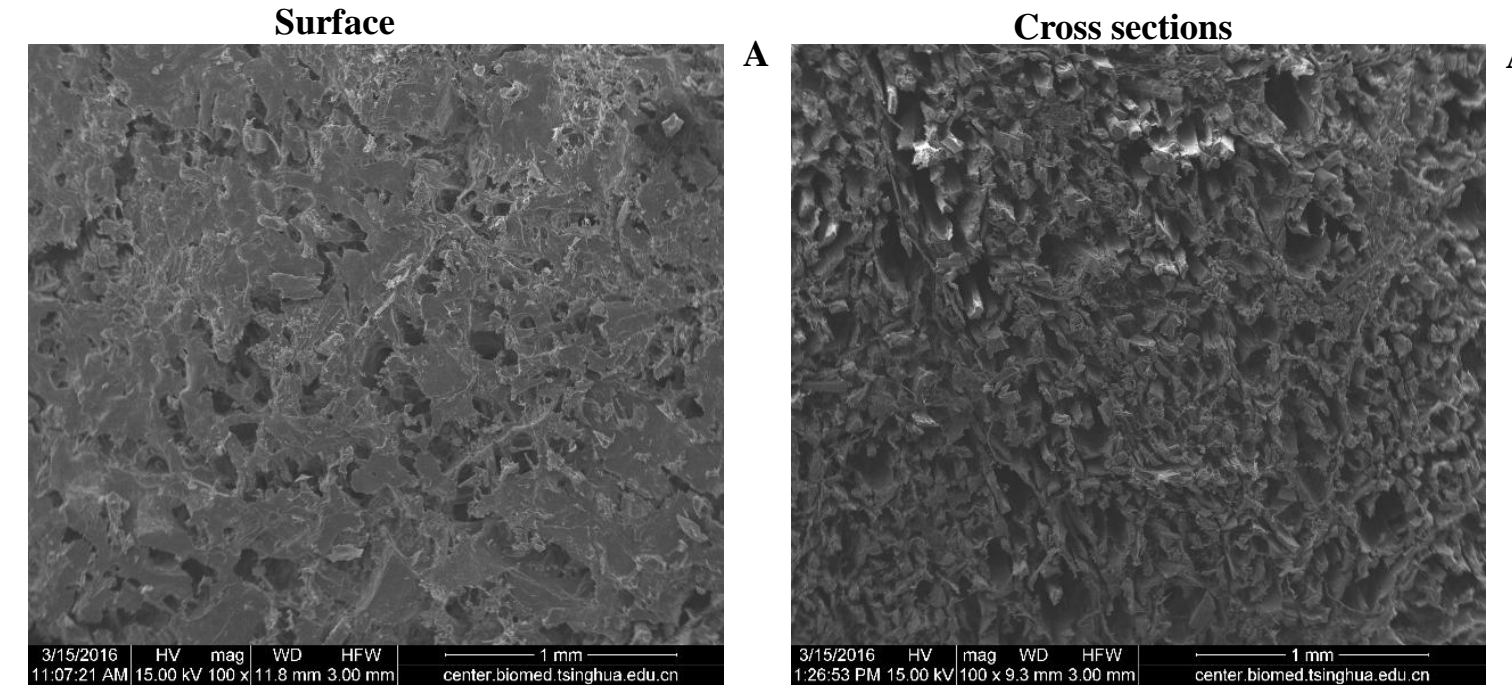

B

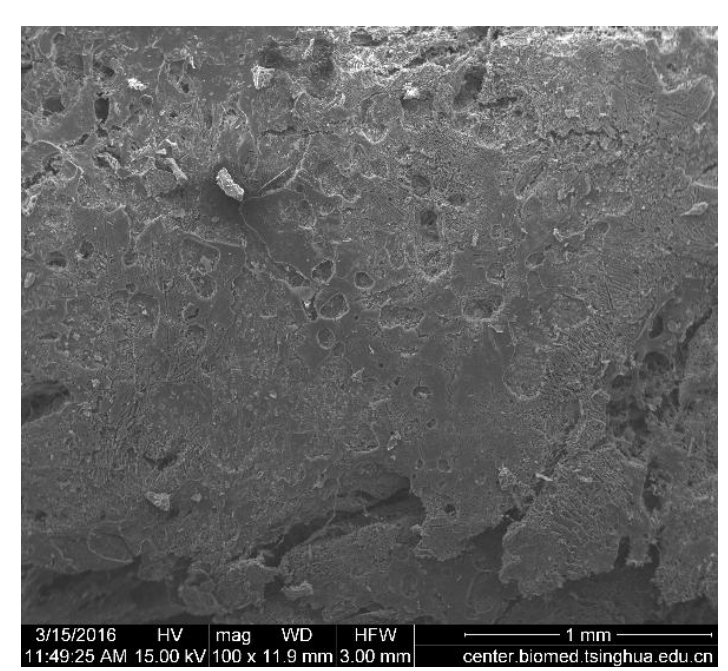

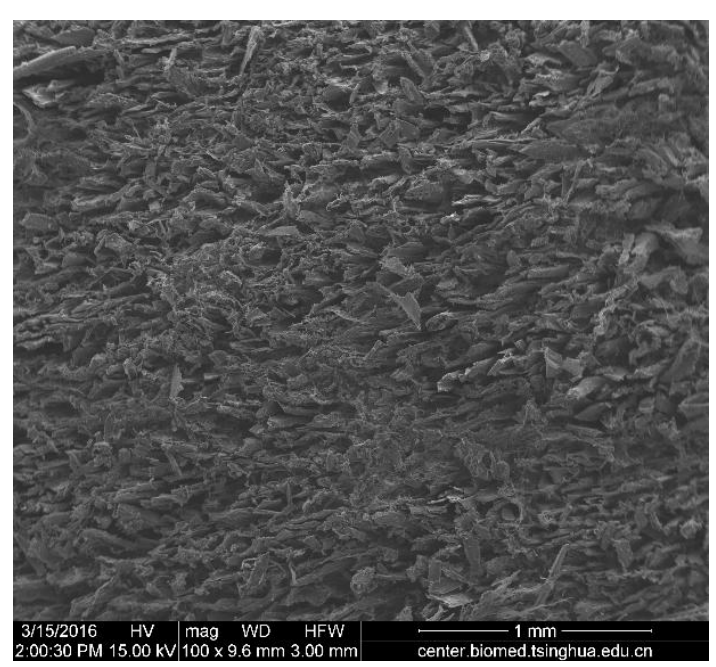

Cross sections
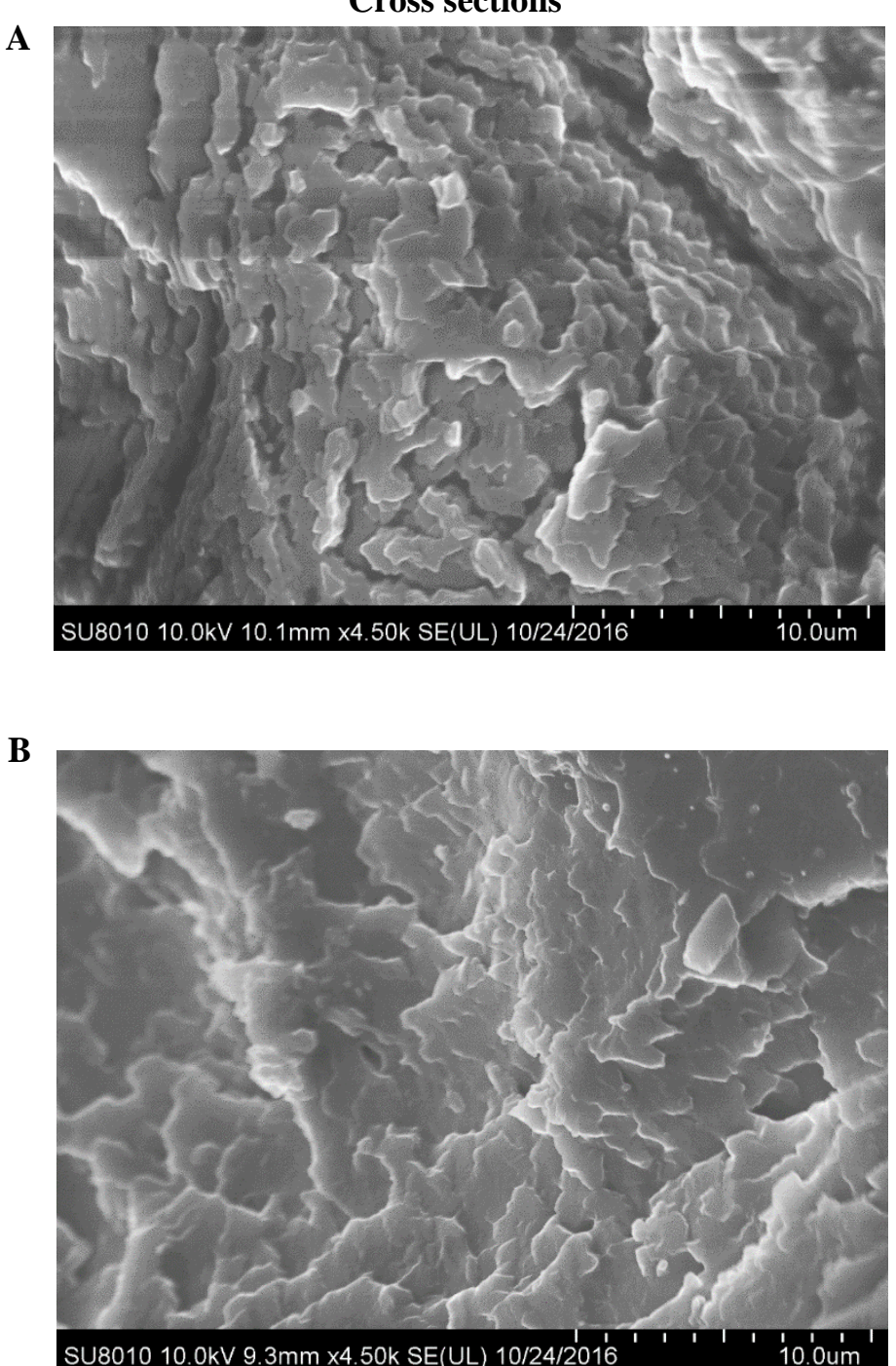

Fig. 5 Scanning electron micrograph of surface and transversal cuts to the fiber direction of pork tenderloin. A, frozen pork; B, frozen pork with $10 \mathrm{kV}$ HVEF treatment. 
A

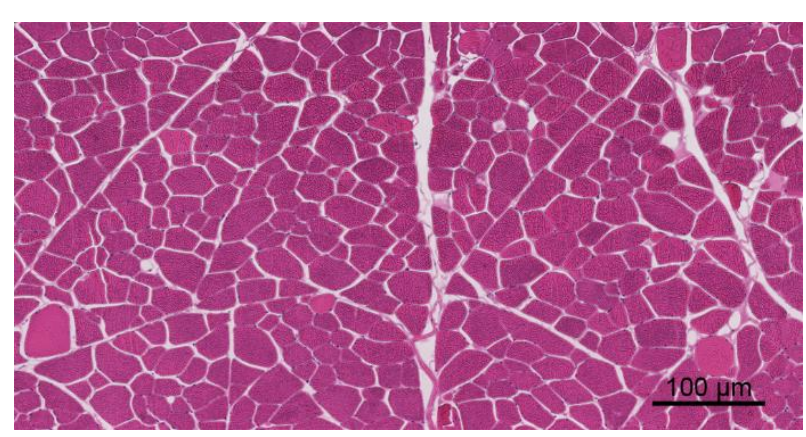

B

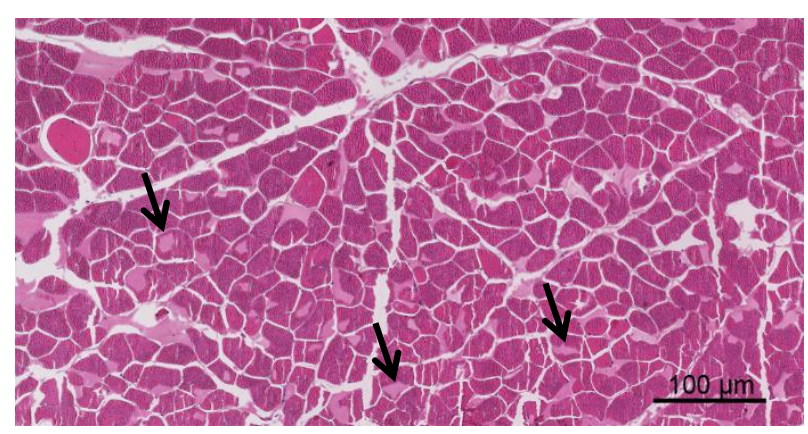

C

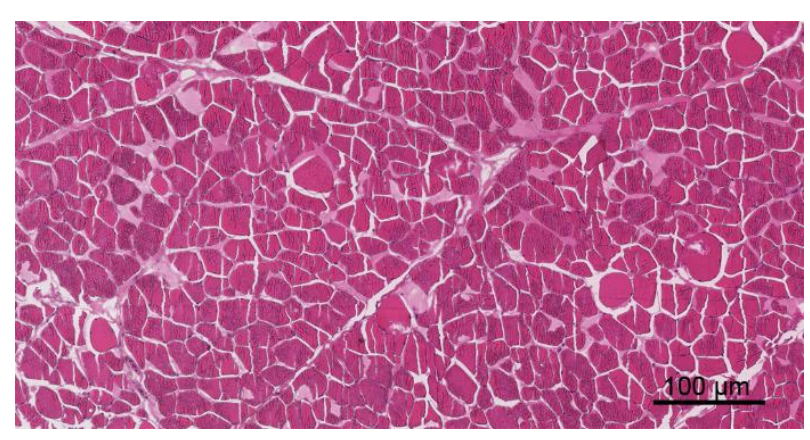

Longitudinal sections
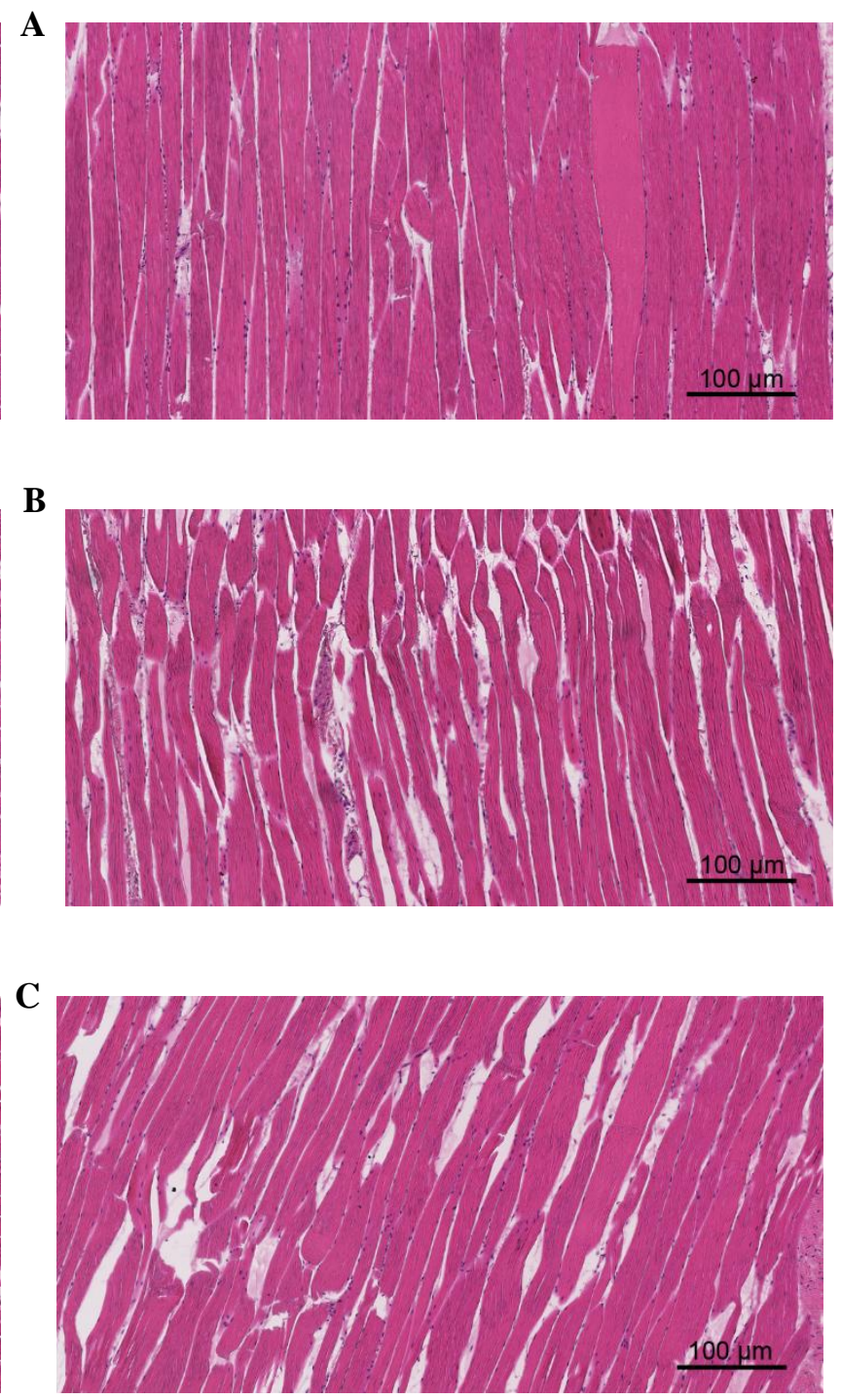

Fig. 6 Light microscopy observations on the cross and longitudinal sections of pork tenderloin. A, fresh pork; B, frozen pork; C, frozen pork with $10 \mathrm{kV} \mathrm{HVEF}$ treatment. The arrow represents the voids in the cells caused by ice crystals. 


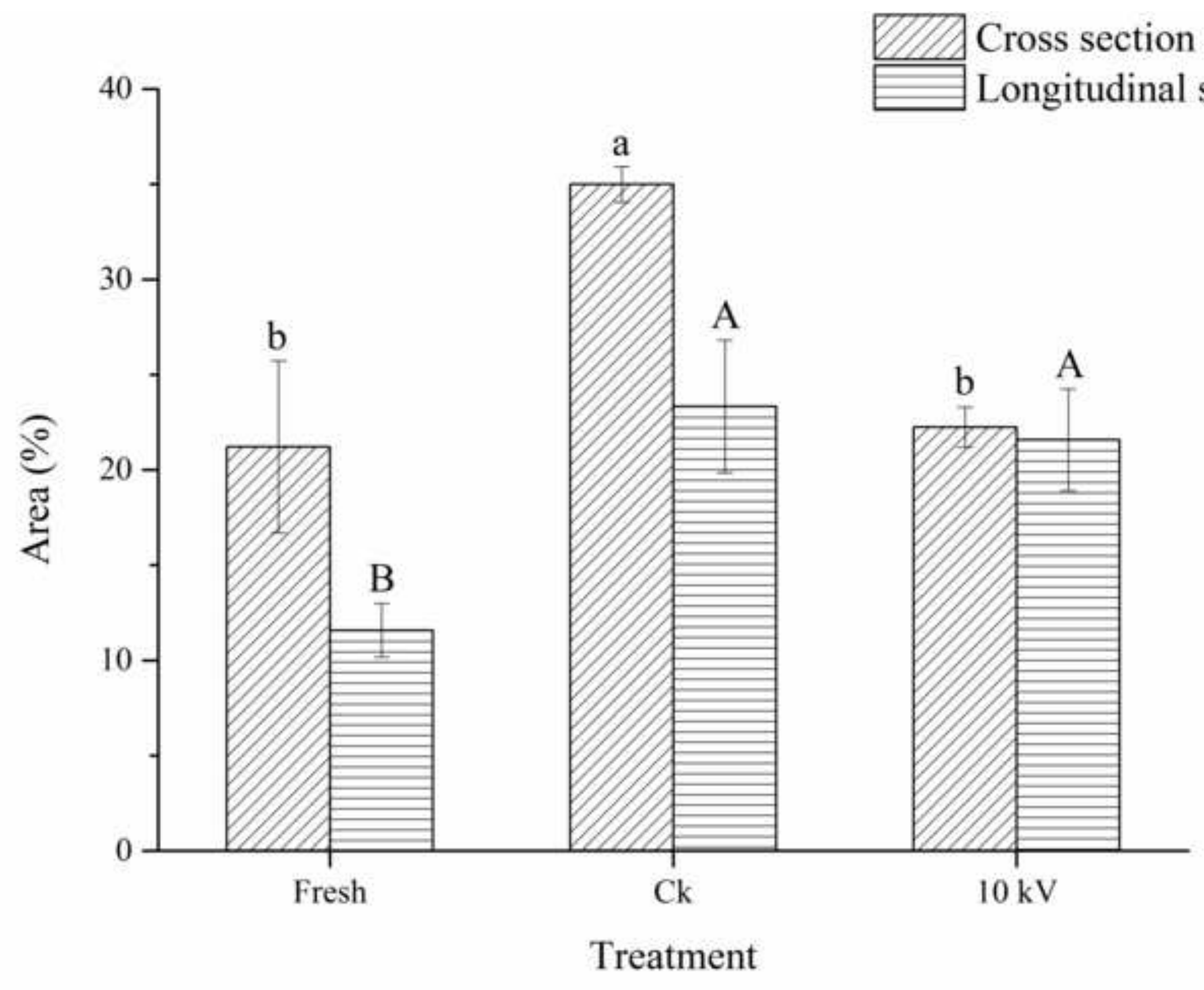

Fig. 7. The area of both extra- and intracellular spaces which were not stained by HE for pork tenderloin. 
Table 1 Effect of DC HVEF treatment on the nucleation temperature $\left(T_{n}\right)$ and phase transition time (crystallization time) of DW.

\begin{tabular}{cccc}
\hline Voltage $(\mathrm{kV})$ & Electrostatic field $(\mathrm{V} / \mathrm{m})$ & $T_{\mathrm{n}}\left({ }^{\circ} \mathrm{C}\right)$ & $t_{\mathrm{c}}(\mathrm{s})$ \\
\hline 0 & 0 & $-5.3 \pm 0.6^{\mathrm{c}}$ & $588 \pm 50^{\mathrm{b}}$ \\
4 & $1.0 \times 10^{5}$ & $-4.7 \pm 0.7^{\mathrm{c}}$ & $720 \pm 112^{\mathrm{b}}$ \\
6 & $1.5 \times 10^{5}$ & $-2.4 \pm 0.9^{\mathrm{a}}$ & $675 \pm 150^{\mathrm{b}}$ \\
8 & $2.0 \times 10^{5}$ & $-3.6 \pm 0.6^{\mathrm{b}}$ & $732 \pm 143^{\mathrm{b}}$ \\
10 & $2.5 \times 10^{5}$ & $-1.8 \pm 1.0^{\mathrm{a}}$ & $900 \pm 49^{\mathrm{a}}$ \\
\hline
\end{tabular}

Results are presented as mean values \pm SD of at least 3 replicates. Different letters in each row indicate significant difference $(P<0.05)$ in $T_{\mathrm{n}}\left({ }^{\circ} \mathrm{C}\right)$ and $t_{\mathrm{c}}(\mathrm{s})$. 
Table 2 Effect of DC HVEF treatment on the freezing point $\left(T_{m}\right)$ and phase transition time (crystallization time) of pork tenderloin.

\begin{tabular}{cccc}
\hline Voltage $(\mathrm{kV})$ & Electrostatic field $(\mathrm{V} / \mathrm{m})$ & $T_{\mathrm{m}}\left({ }^{\circ} \mathrm{C}\right)$ & $t_{\mathrm{c}}(\mathrm{s})$ \\
\hline 0 & 0 & $-1.1 \pm 0.1^{\mathrm{a}}$ & $3480 \pm 433 \mathrm{a}$ \\
4 & $1.0 \times 10^{5}$ & $-1.2 \pm 0.1^{\mathrm{a}}$ & $2840 \pm 35 \mathrm{~b}$ \\
6 & $1.5 \times 10^{5}$ & $-0.9 \pm 0.2^{\mathrm{a}}$ & $3740 \pm 362 \mathrm{a}$ \\
8 & $2.0 \times 10^{5}$ & $-1.1 \pm 0.1^{\mathrm{a}}$ & $3240 \pm 365 \mathrm{ab}$ \\
10 & $2.5 \times 10^{5}$ & $-1.0 \pm 0^{\mathrm{a}}$ & $3680 \pm 242 \mathrm{a}$ \\
\hline
\end{tabular}

Results are presented as mean values \pm SD of at least 3 replicates. Different letters in each row indicate significant difference $(P<0.05)$ in $T_{\mathrm{m}}\left({ }^{\circ} \mathrm{C}\right)$ and $t_{\mathrm{c}}(\mathrm{s})$. 
Table 3 Effect of HVEF treatment on the $T_{2}$ relaxation time and peak area fraction of water in the pork tenderloin.

\begin{tabular}{|c|c|c|c|c|c|c|}
\hline \multicolumn{4}{|c|}{$T_{2}{ }^{\mathrm{e}}(\mathrm{ms})$} & \multicolumn{3}{|c|}{$\mathbf{P P}^{\mathrm{e}}(\%)$} \\
\hline & Peak 1 & Peak 2 & Peak 3 & Peak 1 & Peak 2 & Peak 3 \\
\hline Fresh & $1.16 \pm 0.16^{\mathrm{b}}$ & $41.41 \pm 3.26^{\mathrm{ab}}$ & $307.37 \pm 42.79^{\mathrm{a}}$ & $2.65 \pm 0.44^{\mathrm{b}}$ & $97.13 \pm 0.39^{\mathrm{a}}$ & $0.25 \pm 0.10^{\mathrm{d}}$ \\
\hline $0 \mathrm{kV}$ & $1.92 \pm 0.15^{\mathrm{a}}$ & $37.65^{\mathrm{b}}$ & $231.01^{b}$ & $3.23 \pm 0.32^{\mathrm{ab}}$ & $82.78 \pm 1.26^{\mathrm{d}}$ & $14.00 \pm 1.12^{\mathrm{a}}$ \\
\hline $4 \mathrm{kV}$ & $1.84 \pm 0.15^{\mathrm{a}}$ & $39.53 \pm 3.26^{\mathrm{ab}}$ & $200.92^{b c}$ & $2.93 \pm 0.31^{\mathrm{ab}}$ & $84.03 \pm 2.15^{\mathrm{cd}}$ & $13.03 \pm 2.31^{\mathrm{ab}}$ \\
\hline $6 \mathrm{kV}$ & $1.92 \pm 0.15^{\mathrm{a}}$ & $37.65^{\mathrm{b}}$ & $231.01^{\mathrm{bc}}$ & $2.55 \pm 0.31^{\mathrm{b}}$ & $86.70 \pm 2.19^{c}$ & $10.73 \pm 2.17^{\mathrm{b}}$ \\
\hline $8 \mathrm{kV}$ & $1.92 \pm 0.15^{\mathrm{a}}$ & $39.53 \pm 3.26^{\mathrm{ab}}$ & $183.47 \pm 15.11^{\mathrm{bc}}$ & $2.65 \pm 0.52^{\mathrm{b}}$ & $83.50 \pm 3.13^{d}$ & $13.80 \pm 2.74^{\mathrm{a}}$ \\
\hline $10 \mathrm{kV}$ & $1.89 \pm 0.20^{\mathrm{a}}$ & $43.29^{\mathrm{a}}$ & $220.98 \pm 17.37^{\mathrm{c}}$ & $3.53 \pm 0.51^{\mathrm{a}}$ & $91.83 \pm 1.11^{b}$ & $4.63 \pm 0.81^{c}$ \\
\hline
\end{tabular}

${ }^{\mathrm{e}}$ spin-spin relaxation time.

Results are presented as mean values \pm SD of 3 replicates. Different letters in each row indicate significant difference $(P<0.05)$ in $T_{2}(\mathrm{~ms})$ and PP (\%), respectively. 
Table 4 Effect of HVEF treatment on the $T_{\text {peak }}$ and $\mathrm{DH}$ of the pork tenderloin from DSC analysis.

\begin{tabular}{cccccccc}
\hline & $\boldsymbol{T}_{\text {peak1 }}{ }^{\mathrm{a}}\left({ }^{\circ} \mathrm{C}\right)$ & $\boldsymbol{T}_{\text {peak2 }}{ }^{\mathrm{b}}\left({ }^{\circ} \mathrm{C}\right)$ & $\boldsymbol{T}_{\text {peak3 }}{ }^{\mathrm{c}}\left({ }^{\circ} \mathrm{C}\right)$ & $\boldsymbol{D} \boldsymbol{H}_{\text {peak 1 }}{ }^{\mathrm{A}}(\mathrm{J} / \mathrm{g})$ & $\boldsymbol{D} \boldsymbol{H}_{\text {peak 2 }}{ }^{\mathrm{B}}(\mathrm{J} / \mathrm{g})$ & $\boldsymbol{D} \boldsymbol{H}_{\text {peak 1+2 }}{ }^{\mathrm{D}}(\mathrm{J} / \mathrm{g})$ & $\boldsymbol{D H}_{\text {peak 3 }}{ }^{\mathrm{C}}(\mathrm{J} / \mathrm{g})$ \\
\hline Fresh meat & $59.61 \pm 1.83^{\mathrm{a}}$ & $67.70 \pm 3.49^{\mathrm{a}}$ & $80.27 \pm 1.56^{\mathrm{a}}$ & $-0.16 \pm 0.02^{\mathrm{a}}$ & $-0.13 \pm 0.00^{\mathrm{a}}$ & $-0.28 \pm 0.02^{\mathrm{a}}$ & $-0.32 \pm 0.03^{\mathrm{a}}$ \\
$0 \mathrm{kV}$ & $56.23 \pm 0.87^{\mathrm{b}}$ & $65.89 \pm 0.86^{\mathrm{a}}$ & $81.27 \pm 0.22^{\mathrm{a}}$ & $-0.05 \pm 0.01^{\mathrm{b}}$ & $-0.07 \pm 0.01^{\mathrm{b}}$ & $-0.12 \pm 0.02^{\mathrm{c}}$ & $-0.12 \pm 0.02^{\mathrm{b}}$ \\
$10 \mathrm{kV}$ & $57.11 \pm 0.20^{\mathrm{b}}$ & $65.74 \pm 0.19^{\mathrm{a}}$ & $82.04 \pm 0.49^{\mathrm{a}}$ & $-0.05 \pm 0.00^{\mathrm{b}}$ & $-0.12 \pm 0.01^{\mathrm{a}}$ & $-0.17 \pm 0.006^{\mathrm{b}}$ & $-0.13 \pm 0.03^{\mathrm{b}}$ \\
\hline
\end{tabular}

${ }^{\mathrm{a}, \mathrm{b}, \mathrm{c}}$ Temperature which represented 3 thermal transition temperature in the DSC process.

A, B, C Denaturation enthalpies per gram wet weight. ${ }^{\mathrm{D}}$ Sum of $D H_{\text {peak } 1}$ and $D H_{\text {peak } 2}$.

Results are presented as mean values \pm SD of 3 replicates. Different letters in each row indicate significant difference $(P<0.05)$ in $T_{\text {peak }}\left({ }^{\circ} \mathrm{C}\right)$ and $D H(\mathrm{~J} / \mathrm{g})$, respectively. 
Table 5 Colour parameters, $\mathrm{pH}$ and expressible moisture of pork tenderloin.

\begin{tabular}{|c|c|c|c|c|c|c|c|c|}
\hline & $L^{*}$ & $a^{*}$ & $b^{*}$ & $C$ & $\Delta E$ & Whiteness & $\mathbf{p H}$ & EM (\%) \\
\hline Fresh & $45.01 \pm 0.38^{\mathrm{a}}$ & $5.92 \pm 0.28^{\mathrm{c}}$ & $4.76 \pm 0.73^{b}$ & $7.53 \pm 0.21^{\mathrm{c}}$ & --- & $44.48 \pm 0.34^{\mathrm{a}}$ & $5.72 \pm 0.083^{\mathrm{a}}$ & $22.83 \pm 1.97^{\mathrm{b}}$ \\
\hline $0 \mathrm{kV}$ & $42.83 \pm 0.34^{\mathrm{b}}$ & $9.70 \pm 0.16^{\mathrm{a}}$ & $7.39 \pm 0.87^{\mathrm{a}}$ & $12.21 \pm 0.42^{\mathrm{a}}$ & $5.15 \pm 0.18^{\mathrm{a}}$ & $41.54 \pm 0.25^{\mathrm{b}}$ & $5.55 \pm 0.0058^{b}$ & $32.28 \pm 2.25^{\mathrm{a}}$ \\
\hline $10 \mathrm{kV}$ & $42.28 \pm 0.34^{b}$ & $7.32 \pm 0.50^{b}$ & $2.83 \pm 0.45^{\mathrm{c}}$ & $7.86 \pm 0.41^{\mathrm{b}}$ & $3.67 \pm 0.33^{b}$ & $41.75 \pm 0.28^{b}$ & $5.71 \pm 0.0794^{\mathrm{a}}$ & $30.35 \pm 0.31^{\mathrm{a}}$ \\
\hline
\end{tabular}

Different letters in each row indicate significant difference $(P<0.05)$. 